\title{
Trisomy 15 mosaicism in an IVF fetus
}

\author{
C P Bennett, Teresa Davis, Mary J Seller
}

\begin{abstract}
Prenatal diagnosis of an IVF pregnancy in a woman aged 41 years showed a fetus mosaic for trisomy 15 . The fetus had dysmorphic features, hypoplastic adrenal glands, and an accessory spleen. Both IVF and advanced maternal age would seem to increase the risk of trisomy 15.

( $\mathcal{H}$ Med Genet 1992;29:745-6)
\end{abstract}

Complete trisomy 15 in a livebirth has been reported only once. ${ }^{1}$ In spontaneous abortion surveys it comprises $7 \cdot 6 \%$ of all trisomies, has a mean survival time from conception of 96 days, ${ }^{2}$ and the embryos, if present, are tiny and severely dysmorphic. ${ }^{3}$ Partial trisomy 15 , however, is compatible with postnatal life, although it is not common, and is associated with profound mental retardation, mild microcephaly, and facial dysmorphism. ${ }^{4-6}$ We describe a fetus diagnosed prenatally as mosaic for trisomy 15, which had been conceived through in vitro fertilisation.

\section{Case report}

An unrelated Caucasian couple aged 46 and 41 years, with an adopted son but no children of their own, had had five unsuccessful attempts at in vitro fertilisation. The sixth attempt resulted in a pregnancy which proceeded well until a 16 week maternal serum triple test (St Bartholomew's Hospital, London) gave a positive result, with a risk of Down's syndrome of 1:7. No abnormality could be found on a detailed scan at 18 weeks ( $\mathrm{Mr} \mathrm{K}$ Nicolaides, Harris Birthright Research Centre, King's College Hospital), but following cordocentesis, the karyotype was found to be a mosaic $46, X Y / 47, X Y,+15$. Eight of 30 cells in the fetal blood sample were trisomic. After considerable heart searching, the parents decided on termination of this much wanted pregnancy.

The male fetus (fig 1 and 2) was of a size consistent with dates. There was brachycephaly and a rather low, rounded cranium overall, suggesting mild microcephaly. There was ocular hypertelorism, a small, short nose with anteverted nostrils and a midline groove on the tip, a prominent maxilla and upper lip, high arched palate, and small, low set, posteriorly rotated ears. There was excess skin on the posterior neck, a somewhat short sternum, widely spaced nipples, and the thumbs were bulbous. Internally, there was a small accessory spleen and hypoplastic adrenal glands, one quarter their normal weight. The karyotype of the amnion was also $46, \mathrm{XY} /$ $47, X Y,+15,18$ of 25 cells being trisomic (cells frozen and stored in the Division of Medical

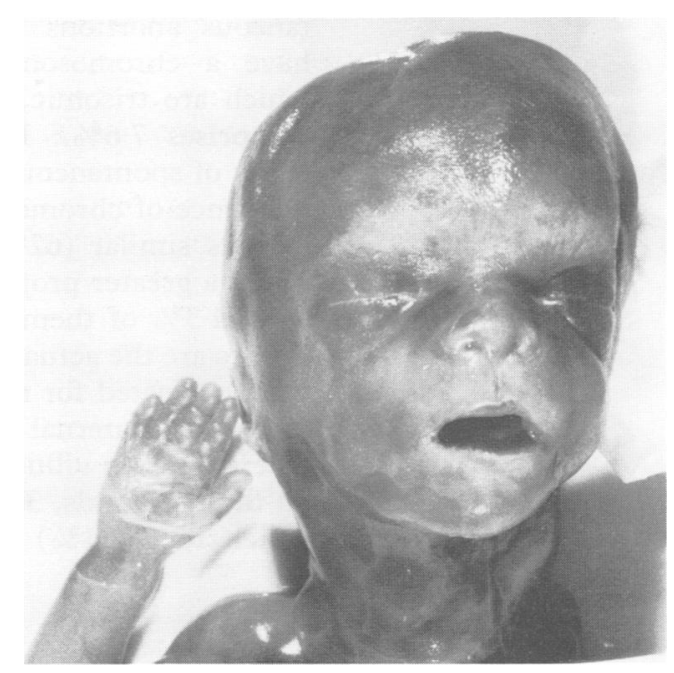

Figure 1 View of face and right hand showing low, rounded cranium, ocular hypertelorism, small, short nose with anteverted nostrils, prominent upper lip, and bulbous thumbs.

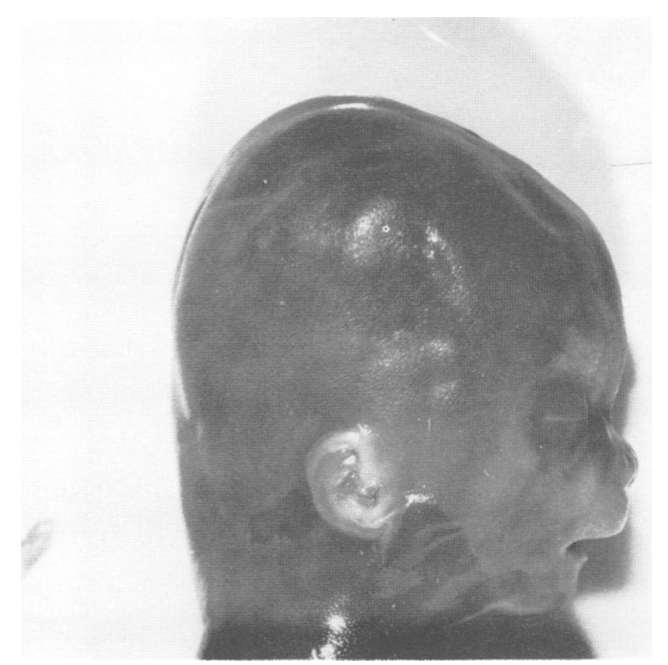

Figure 2 Lateral view of head showing brachycephaly, low set, posteriorly rotated ears, small, short nose, and prominent upper lip and maxilla.

and Molecular Genetics, Guy's Hospital: reference 91/4854), but unfortunately tissue culture was unsuccessful on all four fetal tissues attempted.

\section{Discussion}

The single liveborn case of complete trisomy $15^{1}$ died in the neonatal period. She had numerous abnormalities including a ventricular septal defect and coarctation of the aorta. Several of the dysmorphic facial features in the present mosaic fetus were similar to those 
described in the child, but they are non-specific. The features found in the partial trisomy cases are also not diagnostic.

Trisomy 15 is not common, but there are two factors which might have played a part in the occurrence in the present mosaic case. These are the assisted conception and advanced maternal age. Around $60 \%$ of spontaneous abortions from natural conceptions have a chromosome abnormality, $50 \%$ of which are trisomic, and of these trisomy 15 comprises $7.6 \% .^{2}$ In a combined European study of spontaneous abortions after IVF, the incidence of chromosome abnormalities overall was similar $(62 \%)$, but trisomics contributed a greater proportion of the total $(67 \%)$, and $14.3 \%$ of them were trisomy $15 .{ }^{7}$ These figures are the actual proportions and have not been corrected for maternal age. With regard to raised maternal age, in 758 pregnancies where chorion villus sampling was performed on these grounds, 36 trisomies were found, of which four $(11 \%)$ were trisomy $15 .^{8}$ Thus, both assisted conception and advanced maternal age would seem to be associated with an increased incidence of trisomy 15 and may have been contributory factors in the present case.

1 Coldwell S, Fitzgerald B, Semmens JM, Ede R, Bateman C. A case of trisomy of chromosome 15, I Med Genet 1981;18:146-8.

2 Warburton D, Stein Z, Kline J, Susser M. Chromosome abnormalities in spontaneous abortion: data from the New aork City study. In: Porter IH, Hook EB, eds. Human York City study. In: Porter $\mathrm{HH}$, Hook EB, eds. Human
embryonic and fetal death. New York: Academic Press, embryonic and
1980: $261-87$.

3 Kalousek DK. Anatomic and chromosome anomalies in specimens of early spontaneous abortion: seven-year experience. In: Gilbert EF, Opitz JM, Paul NW, Matson M eds. Genetic aspects of developmental pathology. Birth Defects Vol 23/1. New York: Alan R Liss, 1987:153-68.

4 Webb GC, Garson M, Robson MK, Pitt DB. A partial Dtrisomy/normal mosaic female. $\mathcal{F}$ Med Genet 1971;8:522-7.

5 Castel Y, Riviere D, Boucly JY, Toudic L. Trisomie 15q partielle par translocation maternelle $t(7 ; 15)(\mathbf{q} 35 ; \mathrm{q} 14)$. Ann Genet (Paris) 1976;19:75-9.

6 Anneren G, Gustavson KH. A boy with proximal trisomy 15 and a male fetus with distal trisomy 15 due to a familial 13p:15q translocation. Clin Genet 1982;22:16-21.

7 Plachot M. Chromosome analysis of spontaneous abortions after IVF. A European study. Hum Reprod 1989;4:425-9.

8 Simoni G, Gimelli G, Cuoco C, et al. First trimester fetal karyotyping: one thousand diagnoses. Hum Genet 1986;72:203-9. 